\title{
Profile of Ectopic Pregnancy in Tertiary Level Hospital in Uttarakhand, India
}

\author{
Neeta Bansal*, Anuja Nanda, Vineeta Gupta \\ Department of Gynecology and Obstetrics, Sri Guru Ram Rai institute of Medical \& Health Sciences, \\ Dehradun, India \\ Email: ${ }^{*}$ neetanbansal@gmail.com
}

Received 23 January 2015; accepted 24 March 2015; published 27 March 2015

Copyright (C) 2015 by authors and Scientific Research Publishing Inc.

This work is licensed under the Creative Commons Attribution International License (CC BY).

http://creativecommons.org/licenses/by/4.0/

(c) (1)

\begin{abstract}
Introduction: Ectopic pregnancy is an emergency in obstetric wards and a significant cause of maternal morbidity and mortality. Incidences of ectopic pregnancy are increasing. Life can be saved with quickness and alertness. Objective: The objective of this study is to find out and evaluate the incidence, clinical presentation, risk factors, and management outcomes of ectopic pregnancies at Sri Guru Ram Rai Institute of Medical and Health Sciences (SGRRIMHS), Dehradun, Uttarakhand, India. Method: We did a retrospective study of the patients admitted in our hospital (SMI Hospital, SGRRIMHS) and study period was January 1, 2004 to December 31, 2013. Medical records were studied for management, total admission in obstetric wards, total births. Data were collected with the aid of data-entry forms designed for study. There were 4040 ANC patients admitted, out of which 202 cases were ectopic pregnancies. The relevant data collected were analyzed with SPSS for Windows. Result: Ectopic pregnancy constituted 5.0\% of all ANC cases admitted in our Hospital. The mean age of patients was $25 \pm 2$ years, 192 of $202(95.04 \%)$ had ruptured pregnancies, and remaining $10(4.96 \%)$ were unruptured. The commonest clinical presentation was abdominal pain (162 of $20280.19 \%)$. The commonest $(120$ of $202,59.4 \%)$ cause was past history of induced abortion. 4 deaths $(1.98 \%)$ were recorded. Conclusion: Ecotopic pregnancy is common and recognized cause of maternal morbidity and mortality. It is a recognized risk of induced abortion.
\end{abstract}

\section{Keywords}

Ectopic, Pregnancy, SGRRIMHS

\section{Introduction}

Ectopic pregnancy is a leading cause of maternal mortality and morbidity in the first trimester and accounts for

${ }^{*}$ Corresponding author.

How to cite this paper: Bansal, N., Nanda, A. and Gupta, V. (2015) Profile of Ectopic Pregnancy in Tertiary Level Hospital in Uttarakhand, India. Open Journal of Obstetrics and Gynecology, 5, 185-191. http://dx.doi.org/10.4236/ojog.2015.54026 
$10 \%$ to $15 \%$ of all maternal deaths [1]. In developing countries, it is becoming an important cause of morbidity and mortality. The patients usually present late with rupture and shock [2]. Foetal loss, recurrence and impairment of subsequent fertility are associated with ectopic pregnancy [3].

The true incidence of ectopic pregnancy is difficult to determine [3]. It varies significantly among institutions and countries, depending on the denominator used in its calculations and the facilities available for diagnosis. Currently, the overall incidence is increasing worldwide [3]-[14], but the case-fatality rate has decreased [6] [14]. This might be due to a combination of increasing pelvic inflammatory disease (PID) and better antibiotics that permit tubal patency with luminal damage following infection, and an increase in ovulation induction, assisted reproductive technology, and improved diagnostic techniques [1] [4] [9] [15]. More than 95\% of ectopic pregnancies occur in the fallopian tube, making this the commonest site [1] [4]-[6].

The etiology of ectopic pregnancy is not well clear. Several factors increase the risk of ectopic pregnancy. These risk factors share a common mechanism of action-namely, interference with fallopian tube function. Normally, an egg is fertilized in the fallopian tube and then travels down the tube to the implantation site. Any mechanism that interferes with the normal function of the fallopian tube during this process increases the risk of ectopic pregnancy. The mechanism can be anatomic (e.g., scarring that blocks transport of the egg) or functional (e.g., impaired tubal mobility). Pelvic inflammatory disease, puerperal sepsis, postabortion sepsis, appendicitis, and the use of intrauterine contraceptive devices have been identified as sources of pelvic infection and major risk factors [3] [4] [6]. Other etiological risk factors are tubal/pelvic surgeries, endometriosis, exposure to diethylstilbestrol in utero, chromosomally abnormal embryo, use of progesterone-only pills, cigarette smoking, conception following induction of ovulation and in vitro fertilization and embryo transfer (assisted reproductive technology), history of previous abortion, previous ectopic pregnancy, history of infertility, race, and age above 35 years [5] [9]. However, ectopic pregnancy can also occur without any obvious risk factors [5] [16]-[20].

Rupture ectopic pregnancy could present as acute emergency or subacutely [6]. Presentation can be asymptomatic, before rupture.

Greater awareness of risk factors and improved technology (biochemical markers and ultrasonography) allow ectopic pregnancy to be identified before the development of life-threatening events.

The objective of this study is to find out and evaluate the incidence, clinical presentation, risk factors, and management outcomes of ectopic pregnancies.

\section{Materials and Methods}

This was a retrospective study of all cases of ectopic pregnancies admitted and managed in SMI Hospital (SGRRIMHS), Dehradun from January 1, 2004 to December 31, 2013. It is a tertiary hospital. It received referral from Garhwal region of Uttarakhand state of India. All cases of diagnosed ectopic pregnancy admitted through Emergency Unit or OPD. The diagnosis of ectopic pregnancy was made mainly by history-taking, clinical physical examination, laboratory, and radiological (ultrasound) investigations. The medical records of all the patients admitted and managed for ectopic pregnancy during the study period were retrieved, and relevant data on age, parity, clinical presentation, risk factors, findings at laparotomy, and the outcome of treatment were collected using data-entry forms designed for this purpose. The gynecology and total birth records for the study period were also collected from the gynecology and labor ward record books. All those whose medical records were incomplete or missing were excluded from the study. Statistical analysis was performed using SPSS and the process involved descriptive statistics.

\section{Results}

This study contains results of 4040 ANC patients who were admitted for last 10 years in obstetric department of SGRRIM\&H Sciences, Dehradun. 202 ases were diagnosed as ectopic pregnancy which constituted 5\% of all pregnancy in this institute. The mean age was $27 \pm 3$ years. Table 1 shows the biodemographic characteristics, the majority of patients (90.09\%) were with age group upto 30 years (182 of 202).

52 of 202 (25.7\%) were nulliparous and only 06 of 202 (2.97\%) were multiparous (parity > 3).

Table 2 shows clinical presentations of ectopic pregnancy. 162 of 202 presented with abdominal pain, 152 of $202(75.24 \%)$ had amenorrhoea while 140 of $202(69.30 \%)$ presented with vaginal bleeding. 110 of 202 $(54.45 \%)$ had duration of $\leq 8$ weeks of amenorrhoea (Table 3 ).

The commonest site of ectopic gestation (Table 4) was the ampullary region of fallopian tube (111 of 202, 
Table 1. Demographic characteristics of patients with ectopic pregnancy.

\begin{tabular}{ccc}
\hline Age (years) & Numbers & Percentage \\
\hline Less than 20 & 10 & $4.95 \%$ \\
$20-24$ & 82 & $40.59 \%$ \\
$25-29$ & 90 & $44.55 \%$ \\
$30-34$ & 15 & $7.42 \%$ \\
$35-39$ & 3 & $1.48 \%$ \\
40 and above & 2 & $0.99 \%$ \\
Parity & & $25.74 \%$ \\
0 & 52 & $40.59 \%$ \\
1 & 82 & $24.75 \%$ \\
2 & 50 & $5.94 \%$ \\
3 & 12 & $2.97 \%$ \\
4 & 6 & $100 \%$ \\
Marital status & & $14.85 \%$ \\
Married & 202 & $5.94 \%$ \\
Single & - & \\
Occupation & 160 & \\
House wife & 30 & \\
In office & 12 & \\
Student & & \\
\hline
\end{tabular}

Table 2. Clinical presentation of ectopic pregnancy.

\begin{tabular}{ccc}
\hline Presentation & Number & Percentage \\
\hline Abdominal pain & 162 & $80.19 \%$ \\
Amenorrhoea & 152 & $75.24 \%$ \\
Vaginal bleeding & 140 & $69.30 \%$ \\
Shock & 57 & $28.21 \%$ \\
Diarrhoea & 5 & $2.4 \%$ \\
\hline
\end{tabular}

Table 3. Duration of amenorrhoea.

\begin{tabular}{ccc}
\hline Duration & Number & Percentage \\
$\leq 8$ weeks & 110 & $54.45 \%$ \\
$\leq 9-12$ weeks & 81 & $40.09 \%$ \\
$\leq$ & 11 & $5.44 \%$ \\
\hline
\end{tabular}

Table 4. Site of ectopic pregnancy.

\begin{tabular}{ccc}
\hline Site of ectopic pregnancy & Number & Percentage \\
\hline Ampulla & 111 & $54.95 \%$ \\
Isthmus & 40 & $19.80 \%$ \\
Fimbriae & 27 & $13.36 \%$ \\
Cornual & 18 & $8.91 \%$ \\
Tubo-ovarian & 6 & $2.97 \%$ \\
\hline
\end{tabular}


54.95\%), while lowest occurrence was at tubo-ovarian site (6 of 202, 2.97\%).

120 of 202 (59.40\%) had as past history of induced abortion while 87 of 202 (43.06\%) had pelvic inflammatory disease, as risk factors for ectopic pregnancy (Table 5). Other associated risk factors were previous history of abdominopelvic surgery (11.38\%), previous spontaneous abortion (18.31\%), intra uterine contraceptive device (10.39\%) and previous ectopic pregnancy (5.44\%).

The majority of patients were diagnosed through history taking, physical examination and ultrasound including abdominal abdominal paracentesis (89.43\%) (Table 6).

192 of 202 (95.04\%) patients had ruptured ectopic pregnancies, while 10 (4.96\%) were not rupture (Table 7).

Commonest surgery done was salpingectomy in 175 of 202 (86.63\%), while in only 7 (3.46\%) required salpingo-oophorectomy (Table 8).

$58.3 \%$ of patients had anaemic after surgery. All had severe anaemia and blood transfusions were given.

The fatality rate was $1.98 \%$ (4 of 202) and it was due to excessive haemorrhage and late arrival in hospital (Table 9).

Table 5. Risk factors found in patients with ectopic pregnancy.

\begin{tabular}{ccc}
\hline Risk factor & Number & Percentage \\
\hline Previous induced abortion & 120 & $59.4 \%$ \\
Pelvic inflammatory disease & 87 & $43.06 \%$ \\
Previous spontaneous abtion & 23 & $11.38 \%$ \\
Previous spontaneous abortion & 23 & $11.38 \%$ \\
Intra uterine contraceptive device & 21 & $10.39 \%$ \\
Previous ectopic pregnancy & 11 & $5.44 \%$ \\
\hline
\end{tabular}

Table 6. Diagnostic method.

\begin{tabular}{ccc}
\hline Method & Number & Percentage \\
\hline Ultrasound & 202 & $100 \%$ \\
Paracentesis & 123 & $60.89 \%$ \\
Pregnancy test & 150 & $74.25 \%$ \\
\hline
\end{tabular}

Table 7. Operative finding.

\begin{tabular}{ccc}
\hline Findings & Number & Percentage \\
\hline Ruptured & 192 & $95.04 \%$ \\
Unruptured & 10 & $4.96 \%$ \\
Tubo-ovarian comples & 8 & $3.9 \%$ \\
\hline
\end{tabular}

Table 8. Type of surgical treatment.

\begin{tabular}{ccc}
\hline Surgery & Number & Percentage \\
\hline Salpingectomy & 175 & $86.63 \%$ \\
Salpingectomy and metroplasty & 20 & $9.90 \%$ \\
Salpingo-oophorectomy & 7 & $3.46 \%$ \\
\hline
\end{tabular}

Table 9. Morbidity of ectopic pregnancy.

\begin{tabular}{cc}
\hline Anaemia & $73 \%$ \\
Fever & $24 \%$ \\
Wound sepsis & $0 \%$ \\
UTI & $1.5 \%$ \\
Maternal Death & $1.5 \%$ \\
\hline
\end{tabular}




\section{Discussion}

Ectopic pregnancy is a life threatening emergency in obstetrics. The incidence of ectopic pregnancy our centre is $5 \%$ of all pregnant women admitted. Incidence is higher than developed countries like Sweden and Finland [13] [14] [21]. The incidence is higher than those of various studies within Nigeria [22]-[25]. The increased incidence in our centre, may be in tertiary status and it is a referral centre for complicated cases. This centre also has better diagnostic facilities. The higher incidence is also because of rising trend of ectopic pregnancy. The incidence of ectopic pregnancy was found to be highest in upto 30 years of patients [22]. This was not surprising because this is reproductive age group high sexual activity and risky methods were noted amongst this group [2].

52 of 202 were nulliparous women. This may be because newly married people with early unintended pregnancy often procure unsafe abortions by use of medical abortion pills, which subsequently predisposes them to having an ectopic gestation in future pregnancies. A previous history of induced abortion and pelvic inflammatory disease were major risk factors in our subjects. This could be related to sepsis because of unsafe abortions.

The increase risk of ectopic pregnancy has been attributed to: pelvic inflammatory disease, smoking in women of reproductive age, use of medical abortion pills, and increased use of assisted reproductive technology and increased awareness of ectopic pregnancy [1] [24]-[27].

Morbidity and mortality are quite. Common with ruptured ectopic pregnancy suspicious and early diagnosis is important to save life and reduce costs.

Abdominal pain and vaginal bleeding were most common clinical presentation in our study [23] [27] [28]. Amenorrhoea and vaginal bleeding were other common clinical presentation [23] [27]. However some studies have shown that about $10 \%$ - 20\% of ectopic pregnancies may present without vaginal bleeding [19]. There are no specific clinical feature that is pathognomic for ectopic pregnancy.

Signs of shock, including hypotension, tachycardia and rebound tenderness were usually present with ruptured ectopic pregnancy. Our diagnosis was based on history, physical examination and abdominal paracentesis. Pregnancy tests were used as supportive diagnostic investigations, with diagnosis confirmed by transabdominal ultrasound scan.

The commonest site of ectopic pregnancy from our findings was the ampullary region of the fallopian was the ampullary region of the fallopian tube, which has also been reported by other studies [3] [17] [21].

Many ectopic pregnancies with low $\beta$-hcg (<200) can be treated expectantly [1] [5] [6].

Shock due to massive blood loss often result in life threatening morbidity and mortality. Immedate surgery after resuscitation is both diagnostic and therapeutic [29]. Immediate intravenous fluid and blood, emergency laprotomy with salpingectomy and conservation of ovaries, was done to most of patients to save life.

Salpingectomy was the most commonest surgical procedure performed to save life, as most of cases were ruptured ectopic pregnancies with massive hemoperitoneum. This method remains the mainstay of treatment [2]-[4], in developing countries, even some scholars have recommended conservative surgeries 30. The chance of intrauterine pregnancy in subsequent pregnancies is $40 \%$ after salpingectomy, $60 \%$ after conservative tubal surgery and $87 \%$ after medical treatment [3].

Anaemia was the commonest complication and it was because of excessive blood loss. The blood was transfused in most of patients which placed additional burden on already compromised health resources.

The case fatality rate in our study is 1.98\%; similar to other studies [30]-[33]. To prevent morbidity and mortality in ectopic pregnancies must include early access to care and promote awareness.

\section{Conclusion}

As incidence of ectopic pregnancy is rising, it is necessary to detect and treat early. This could be achieved by providing adequate materials, manpower and equipment of health and efficient referral system and use of medical pill over the counter without doctor's prescription should be banned.

\section{References}

[1] Igwegbe, A.O., Eleje, G.U., Ugboaja, J.O. and Ofiaeli, R.O. (2012) Improving Maternal Mortality in Nnamdi Azikiwe University Teaching Hospital, Nnewi, Nigeria. International Journal of Gynecology \& Obstetrics, 116, 197-200. http://dx.doi.org/10.1016/j.ijgo.2011.10.023

[2] Udigwe, G.O., Umeononihu, O.S. and Mbachu, I.I. (2010) Ectopic Pregnancy: A 5-Year Review of Cases at Nnamdi Azikiwe University Teaching Hospital (NAUTH). Nigerian Medical Journal, 51, 160-163. 
[3] Rose, I.A., Ayodeji, Olalekan, O.B. and Sylvia, A. (2005) Risk Factors for Ectopic Pregnancy in Lagos, Niger. Acta Obstetricia et Gynecologica Scandinavica, 84, 184-188. http://dx.doi.org/10.1080/j.0001-6349.2005.00684.x

[4] Davor, J. (2007) Ectopic Pregnancy. In: Edmonds, D.K., Ed., Dewhurst's Text Book of Obstetrics and Gynaecology, 7th Edition, Blackwell Science, Oxford, London, 106-116.

[5] Sotubo, O. and Aboyeji, A.P. (1994) Ectopic Pregnancy in Ilorin, Nigeria: A Five-Year Review. Nigerian Medical Practitioner, 27, 25-27.

[6] Baffoe, S. and Nkyekyer, K. (1999) Ectopic Pregnancy in Korle Bu Teaching Hospital, Ghana: A Three-Year Review. Tropical Doctor, 29, 18-22.

[7] Ola, E.R., Imosemi, D.O., Egwuatu, J.I. and Abudu, O.O. (1999) Ectopic Pregnancy in Lagos University, Teaching Hospital; Experience over a Five-Year Period. Nigerian Quarterly Journal of Hospital Medicine, 9, 100-103. http://dx.doi.org/10.4314/nqjhm.v9i2.12355

[8] Symonds, I.M. (1998) Ectopic Pregnancy: Modern Management of Ectopic Pregnancy. Current Opinion in Obstetrics and Gynecology, 8, 27-31. http://dx.doi.org/10.1016/S0957-5847(98)80007-3

[9] Cates Jr., W., Rolfs, R.T. and Aral, S.O. (1990) Sexually Transmitted Diseases, Pelvic Inflammatory Disease and Infertility: An Epidemiology Update. Epidemiologic Reviews, 12, 199-220.

[10] Tenore, J.L. (2000) Ectopic Pregnancy. American Family Physician, 61, 1073-1079.

[11] Akabr, N., Shami, N., Anwar, S. and Asif, S. (2002) Evaluation of Predisposing Factors of Tubal Pregnancy in Multigravidas versus Primigravidas. J Surg PIMS., 25, 20-23.

[12] Braun, R.D. (2005) Surgical Management of Ectopic Pregnancy. E-Medicine, Online 2005.

[13] Sowter, M.C., Farquhar, C.M., Petrie, K.J. and Gudex, G. (2001) A Randomized Trial of Comparing Single Dose Systemic Methotrexate and Laparoscopic Surgery for the Treatment of Unruptured Tubal Pregnancy. British Journal of Obstetrics and Gynaecology, 108, 192-203.

[14] Royal College of Obstetrician-Gynaecologists (RCOG) (2004) The Management of Tubal Pregnancy. Scientific Advisory Committee, Clinical Green Top Guidelines No. 21, RCOG, London, 125-133.

[15] Egger, M., Low, N., Smith, G.D., Lindblom, B. and Hermann, B. (1998) Screening for Chlamydia Infections and the Risk of Ectopic Pregnancy in a Country in Sweden: Ecological Analysis. British Medical Journal, 316, 1776-1780. http://dx.doi.org/10.1136/bmj.316.7147.1776

[16] Glezerman, M., Press, F. and Carpman, M. (1992) Culdocentesis Is an Obsolete Diagnostic Tool in Suspected Ectopic Pregnancy. Archives of Gynecology and Obstetrics, 252, 5-9. http://dx.doi.org/10.1007/BF02389600

[17] Jongen, V.H. (1996) Ectopic Pregnancy and Culdo-Abdominocentesis. International Journal of Gynecology \& Obstetrics, 55, 75-76. http://dx.doi.org/10.1016/0020-7292(96)02712-9

[18] Elson, J., Tailor, A., Benerjee, S., Salim, R., Hillaby, K. and Jurkovic, D. (2004) Expectant Management of Tubal Ectopic Pregnancy: Predication of Successful Outcome Using Decision Tree Analysis. Ultrasound in Obstetrics \& Gynecology, 23, 552-556. http://dx.doi.org/10.1002/uog.1061

[19] Orji, E.O., Fasubaa, O.B., Adeyemi, B., Dare, F.O., Onwudiegwu, U. and Ogunniyi, S.O. (2002) Motality and Morbidity Associated with Misdiagnosis of Ectopic Pregnancy in Defined Nigerian Population. Journal of Obstetrics and Gynaecology, 22, 548-550. http://dx.doi.org/10.1080/0144361021000003744

[20] Uzelac, P.C. and Garmel, S.H. (2007) Early Pregnancy Risk. In: Decherrney, A.H., Nathan, L., Goodwin, T.M. and Laufer, N., Eds., Current Diagnosis and Treatment, Obstetrics and Gynecology, 10th Edition, McGraw Hill Medical Publishing Division, New York, 259-272.

[21] Lewis, G.M. and Drife, J.O. (2004) Why Mothers Die 2000-2002: The Sixth Report of the Confidential Enquiries into Maternal Death in the United Kingdom 2000-2002. RCOG Press, London.

[22] Onwuhafua, P.I., Onwuhafua, A., Adesiyun, G.A. and Adze, J. (2001) Ectopic Pregnancies at Ahamdu Bello University Teaching Hospital, Kaduna Northern Nigeria. Tropical Journal of Obstetrics and Gynaecology, 18, 82-86. http://dx.doi.org/10.4314/tjog.v18i2.14436

[23] Anorlu, R.I., Oluwole, A., Abudu, O.O. and Adebajo, S. (2005) Risk Factors for Ectopic Pregnancy in Lagos, Nigeria. Acta Obstetricia et Gynecologica Scandinavica, 84, 184-188. http://dx.doi.org/10.1080/j.0001-6349.2005.00684.x

[24] Ikeme, A.C. and Ezegwui, H.U. (2005) Morbidity and Mortality Following Tubal Ectopic Pregnancies in Enugu Nigeria. Journal of Obstetrics and Gynaecology, 25, 596-598. http://dx.doi.org/10.1080/01443610500239552

[25] Aboyeji, A.P., Fawole, A.A. and Ijaiya, M.A. (2002) Trends in Ectopic Pregnancy in Ilorin, Nigeria. Nigerian Journal of Surgical Research, 4, 6-11. http://dx.doi.org/10.4314/njsr.v4i1.12163

[26] Oronsaye, A.U. and Odiase, G.I. (1981) Incidence of Ectopic Pregnancy in Benin City, Nigeria. Tropical Doctor, 11, 160-163. 
[27] Igberase, G.O., Ebeigbe, P.N., Igbekoyi, O.F. and Ajufoh, B.I. (2005) Ectopic Pregnancy: An 11-Year Review in Tertiary Center in the Niger Delta. Tropical Doctor, 35, 175-177. http://dx.doi.org/10.1258/0049475054620888

[28] Adinma, J.I. (2002) An Overview of the Global Policy Consensus in Women's Sexual and Reproductive Rights: The Nigerian Perspective. Tropical Journal of Obstetrics and Gynaecology, 19, 509-512.

[29] Eze, J.N., Obuna, J.A. and Ejikeme, B.N. (2012) Bilateral Tubal Ectopic Pregnancies: A Report of Two Cases. Annals of African Medicine, 11, 112-115. http://dx.doi.org/10.4103/1596-3519.93535

[30] Azizia, M., Phadnis, S. and Irvine, L.M. (2006) Surgical Management of Ectopic Pregnancy in a District General Hospital. Journal of Obstetrics and Gynaecology, 26, 656-662. http://dx.doi.org/10.1080/01443610600913817

[31] Dutta, D.C. (2011) Haemorrhage in Early Pregnancy. In: Konar, H., Ed., Textbook of Obstetrics, 7th Edition, New Central Book Agency (P) Ltd., London, 177-182.

[32] Makinde, O.O. and Ogunniyi, S.O. (1990) Ectopic Pregnancy in Ile Ife, Nigeria: Analysis of 203 Cases. Nigerian Medical Journal, 20, 23-25.

[33] Gharoro, E.P. and Igbafe, A.A. (2002) Ectopic Pregnancy Revisited in Benin City, Nigeria: Analysis of 152 Cases. Acta Obstetricia et Gynecologica Scandinavica, 81, 1139-1143. http://dx.doi.org/10.1034/j.1600-0412.2002.811207.x 